\title{
SEMICONDUCTOR MATERIALS FOR FUTURE DISPLAY DEVICES $\dagger$
}

\author{
T. L. TANSLEY and S. J. T. OWEN \\ Department of Electrical \& Electronic Engineering, University of Nottingham, \\ University Park, Nottingham, NG7 2RD, U.K.
}

(Received September 15, 1975; in final form January 5, 1976)

"There can be no economy where there is no efficiency" Benjamin Disraeli (1804-1881)

\begin{abstract}
The large majority of solid state lamps currently available take advantage of the phenomenon of electroluminescent recombination at forward biased $\mathrm{p}-\mathrm{n}$ junctions (homojunctions) in III $-\mathrm{V}$ compound semiconductors or related derivatives ( $\mathrm{GaP}, \mathrm{GaAsP}$, etc.). The range of colours, sizes and luminous efficiencies likely to become available are subject, however, to certain fundamental limitations of the materials used. These are related to the size and nature of the forbidden energy gap, crystal defect structure as well as other factors. Applications will also be limited by the range of promising non-semiconductor display systems in advanced stages of development against which large LED arrays will not be able to compete.

Restricting these applications to the more viable small alphanumerics and indicator lamps, however, alternative semiconductor materials with extremely attractive physical properties exist, although other problems take the place of those mentioned above. For example, most of the II-VI compound semiconductors (CdS, ZnSe, etc.) cannot be doped both $n$ and $p$ type, precluding the manufacture of $p-n$ diode lamps.

In this paper the desirable properties of materials to be developed for future lamp applications are briefly discussed, against background data on current materials, semiconductor materials fulfilling these criteria are introduced and ways in which existing technological difficulties may be circumvented are described.

The paper is concluded with comments upon arguably the most interesting development of recent years, the interfacing of silicon with low voltage excitable "phosphors" in the form of oriented epitaxial semiconductor films. Preparation, properties and advantages in direct integration with SIC addressing machinery are outlined.
\end{abstract}

\section{INTRODUCTION}

Consideration of the economics of first germanium, then silicon and now gallium arsenide semiconductor devices clearly shows that development enters its costliest stage as the respective materials are brought to an acceptable device grade ${ }^{1}$. Acceptability includes the requirement that high grade material must be available in quantity, at low cost, and the process is characterised by the familiar decay of device unit cost from an introductory high level. Only dire necessity will cause the acceptance of materials innovation and the abandonment of an existing device technology in this situation.

$\nmid$ Present address: Department of Electrical \& Computer Engineering, Oregon State University, Corvallis, Oregon 97331.

\$Based in part on a presentation at Semiconductor International, Wiesbaden, W. Germany, 1975.
In the general field of display it is well known that silicon cannot exceed a very small luminescent efficiency, and then only in the infra-red. Thus semiconductor display devices have inevitably been outside the mainstream of solid state device technology, although the processingg of several of the III-IV compounds, and their ternary derivatives in single crystal form has now become fairly routine. For device applications, however, it is never wise to dismiss silicon entirely; the impatt diode, for example, now operates at microwave frequencies which might once have been thought the prerogative of transferred electron devices. It will shortly be shown that silicon has still something to offer in display devices too.

Although it is beyond the scope of this article to discuss display devices based on materials other than semiconductors (for a comprehensive review see the series of articles in Proc. IEEE of July, 1973) these are included for completeness in Figure 1. Amongst 


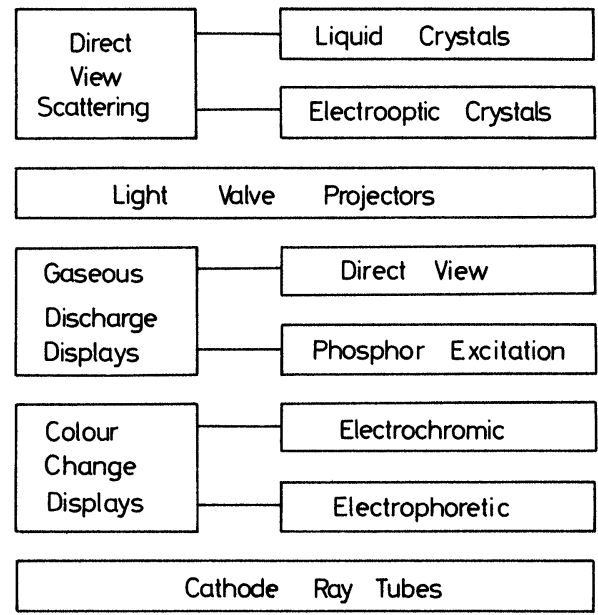

FIGURE 1 Display systems.

the direct-view scattering displays a variety of liquid crystals $\mathbf{s}^{\hat{2}}$ are now available and fairly familiar, and their solid state counterparts, electro-optical crystals, are becoming so, particularly lanthanium doped lead zirconate-titanate (PLZT) ${ }^{3}$.

Light valve projection displays, which use ferroelectric material (Potassium dihydrogen phosphate in the "Titus" tube ${ }^{4}$ for example), operate in the rather different "modulated projector slide" mode.

Gaseous discharge displays are also well established in either direct emission ${ }^{5}$ or phosphor excitation ${ }^{6}$ format. Whilst electrochromicity in its general sense may overlap other listed categories, it is included separately to encompass electrochemical colour changes in solution and cathodochromic effects incorporated as a storage or dark display facility in
Cathode Ray Tubes ${ }^{7}$. Electrophoresis is categorised separately as it involves problems of colloidal migration quite distinct from other display-viable colour change phenomena ${ }^{8}$. Finally, the cathode ray tube itself is the device for which the protagonists of the several alternatives listed are trying to find a replacement. The aim is to achieve lower cost, more compactness, greater reliability and to use less power at lower voltages without losing either the versatility, addressability or scarce materials economy of the CRT.

Much less dramatic requirements are for solid state equivalents of the "nixie" tube or, more basically, the tungsten filament or gaseous discharge indicator lamp. These two applications are intrinsically better suited to a solid state solution of the problem, as evidenced by the wide variety of light emitting diodes (LED) and alphanumeric displays presently available. There are, however, limitations to what can be achieeved with single crystal III-V compound semiconductor injection electroluminescence. The main part of this paper is concerned with how these limitations can be in principle surpassed in other materials, what can probably be achieved in practice, and what novel materials and devices in the research stage have actually been made and operated.

\section{DISPLAY REQUIREMENTS}

Two sets of requirements must be met in order to introduce a new material or device technology. Firstly, it has to be possible to make the device and, secondly, the end product must fulfil the particular set of demands for which it was designed. The relevant factors are listed in Figure 2.
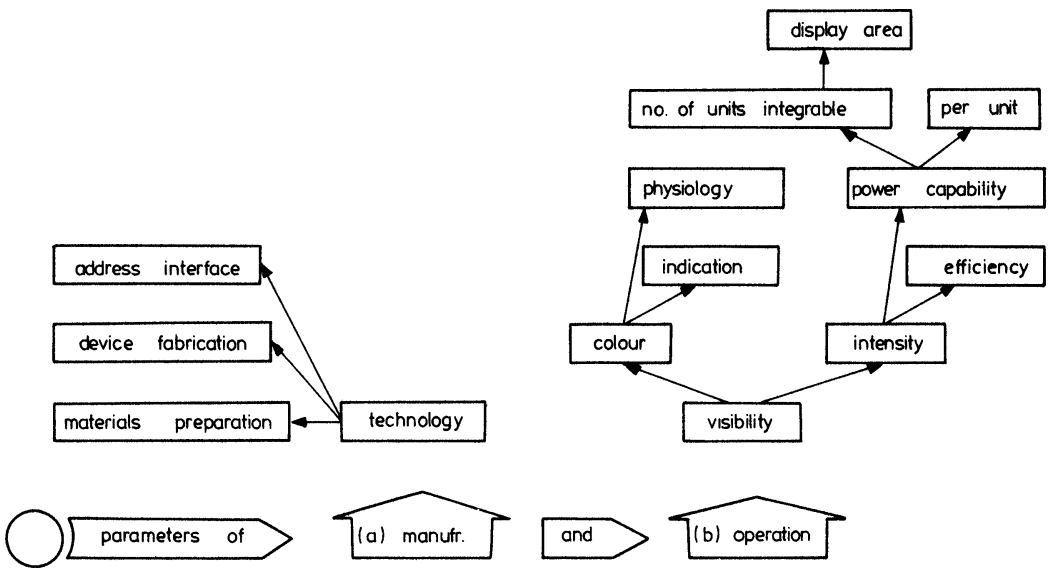

FIGURE 2 Basic requirements for display innovation. 
Bearing in mind the introductory remarks, it is desirable that materials preparation and device fabrication should either take place in existing capital equipment or at least by known techniques.

Specifically, since light emitting diodes are manufactured from III-V compound semiconductors such as $\mathrm{GaP}$ and its derivatives, it would be advantageous to progress towards use of III-V compounds but we shall shortly see that this is unlikely to materialise. On the other hand address logic is, at the moment, well beyond even $\mathrm{GaAs}$ technology, necessitating either hybridised or wired interfacing with silicon ICs. Thus address interfacing at this level is unlikely to be much more difficult for new devices than for existing $\mathrm{GaP}$ matrices. In short, any new semiconductor material developed for display will be sufficiently far outside current industrial practice for continuity to play little part in its choice, whilst address interfacing is at the moment not generally integrable with the display function, so that substitution of one output device for another is not likely to pose any insurmountable problems.

The right hand tree of Figure 2 summarises the factors important in ab initio design of a display material. A full spectral choice of colours is unlikely to be practicable, however indicator applications will require a set of reasonably monochromatic and distinct values including blue, for which there is presently no suitable material, while general alphanumeric applications will favour emission in the 530 to $580 \mathrm{~nm}$ spectral range for which the sensitivity of the eye is within $10 \%$ of its maximum.

Available LEDs, whilst steadily improving, are not noted for high luminous efficiency. The red-emitting diodes, which have a higher quantum efficiency, are currently limited to about $200 \mathrm{~mL} / \mathrm{W}$ compared with about $400 \mathrm{~mL} / \mathrm{W}$ for GaAsP yellow/green, although only $0.05 \%$ power efficiency is involved in the latter case. The comparison with tungsten filament torch bulbs $(\sim 10 \mathrm{~L} / \mathrm{W})$ and the best street lighting $(\sim 100 \mathrm{~L} / \mathrm{W})$ is disconcerting and it must be recognised that the indirect band gap of $\mathrm{GaP}$ will not permit significant improvement on these figures. $U p$ to $20 \%$ quantum efficiency can be obtained from direct gap gallium arsenide in the infra-red frequency band and it is thus preferred for almost all optoelectronic signal processing applications.

The question of power capability and efficiency are intimately related since the display device must also handle the input power not contributing to luminous output. Device geometry, relation to assembly of discrete components into single alphanumeric or larger arrays, and heat sinking, are relevant factors which will not be discussed further here.

Having discussed the generalities associated with the somewhat conflicting requirements of viable technology, choice of colour and high efficiency, we now proceed to discuss in practical terms what has been proved to be possible in choice of novel luminescent materials and device innovation.

\section{PRACTICAL MATERIALS AND DEVICES}

\subsection{Available Semiconductor Materials}

The distribution of energy gap, $E_{g}$, in the semiconductors available to research in quasi-single crystal or thin film form, is shown in Figure $3^{9}$. On the right hand side of the figure the forbidden energy gap, $E_{g}$, is translated into equivalent photo wavelength with some spectral colours indicated. This wavelength may not coincide with the wavelength of peak emission, since the impurity centres or exciton states responsible for enhancing recombination, particularly in indirect energy gap materials, invariably have a smaller separation in energy than the respective band edges. The difference from $E_{g}$ is frequently, but by no means always, small. In addition to the equivalent photon wavelength of

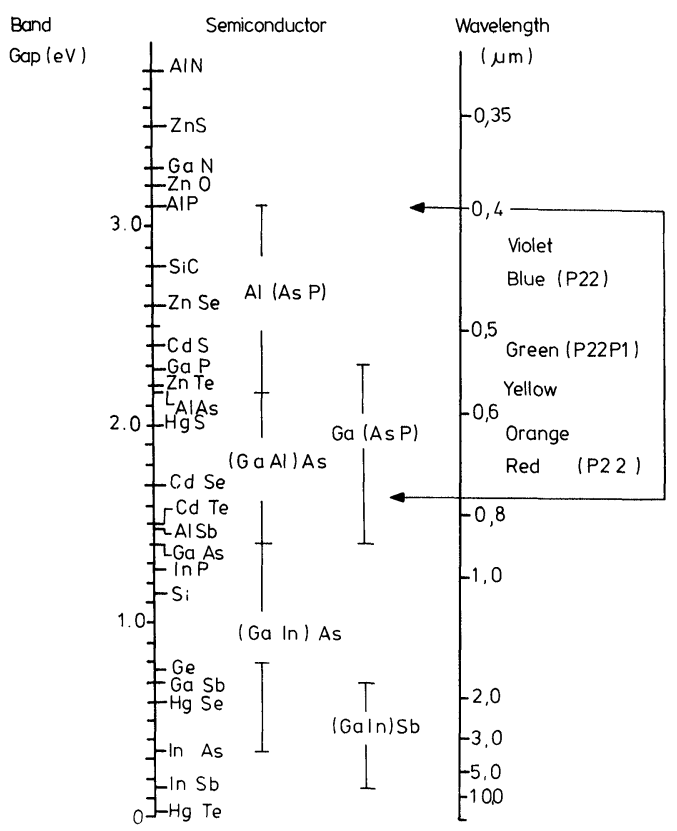

FIGURE 3 Semiconductor parameters. 
the band gap, the approximate dominant emission energies of four familiar phosphors ${ }^{10}$ are included. These are manganese doped zinc orthosilicate or willemite (P1) which is used to give the familiar green emission in oscilloscopes, and the three colour television phosphors (P22).

The figure shows that at least half the available materials may be dismissed on grounds of an insufficient energy gap $\left(E_{g}<2 \mathrm{eV}\right)$ to permit visible radiative recombination, irrespective of other considerations. The remaining materials may be subdivided as follows.

\subsubsection{Aluminium nitride, phosphide and arsenide}

Both aluminium phosphide and arsenide are unstable in normal environments, additionally the decomposition of the arsenide yields highly toxic arsine vapour. Recent work on aluminium nitride suggests that the previously accepted value of energy gap is a spurious result of poor material and that the stoichiometric semiconductor is in fact a non-dopable insulator with a $6 \mathrm{eV}$ band gap ${ }^{11}$. At least $50 \mathrm{~mol}$ per cent AlAs can be stably alloyed with $\mathrm{GaAs}$, a fact taken advantage of in the fabrication of ( $\mathrm{GaAl}) \mathrm{As}-\mathrm{GaAs}$ single and double heterostructure lasers ${ }^{12-14}$. The preparation of the alloy by conventional vapour and liquid-phase epitaxy techniques is possible, as is the formation of $p-n$ junctions suitable for LED applications. This is an established materials technology and will not be discussed further in this paper.

\subsubsection{Gallium phosphide and nitride}

Altnough limited to the green to red portion of the visible spectrum, $\mathrm{GaP}$ and its derivatives are by far the most important group of materials in existing LED use $^{15}$ and as such also fall outside the scope of this paper. The practical use of reverse biased Schottky barrier diodes in semi-insulating $\mathrm{GaN}$ has been reported by Pankove and co-workers ${ }^{16,1} 7$ who have demonstrated blue-green seven-segment alphanumeric displays using his material ${ }^{18}$. Epitaxial n-type material on sapphire substrates is grown by the reaction of gallium chloride and ammonia ${ }^{19}$. The surface of this can be rendered semi-insulating however by the controlled incorporation of impurities such as zinc which, as a deep acceptor level, performs a function which the mobile holes cannot achieve in the depletion region of an n-type material. Electrons fall into these traps with a radiated energy loss whose value depends upon the depth and therefore upon the chemical identity of the impurity, so that the colour of the emission can be preselected by choosing the appropriate compensating dopant. With the use of $\mathrm{Au}, \mathrm{Cu}, \mathrm{Li}, \mathrm{Cd}$ and $\mathrm{Zn}$ as impurities, operation is possible over most of the visible spectrum, i.e. is not limited to band gap emission, although the necessary physical basis for achieving controlled emission has not yet been established. This metal/semi-insulating $\mathrm{GaN} / \mathrm{n}^{+} \mathrm{GaN}$ diode is virtually electrically symmetrical and in fact works for either direction of applied voltage, although the more efficient process is with the metal as cathode. The high fields possible with gold or tungsten point contact Schottky diodes on GaN have also generated violet electro-luminescence ${ }^{20}$.

It has recently been shown, also, to be possible to incorporate $\mathrm{GaN}$ in the quasi-binary III-V compound $\mathrm{Ga}_{x} \mathrm{In}_{1-x} \mathrm{~N}^{21}$ which may be more amenable to existing ternary compound technology than the refractory nitride.

\subsubsection{Silicon carbide}

Like GaN the IV-IV compound silicon carbide is a difficult material to prepare $22-24$ but this is offset by the ease of counterdoping to form $p-n$ junctions and by the potential efficiency obtainable for blue emission, the responsible mechanisms having been discussed at some length in the literature $25-27$. The most promising material at present is prepared by the reaction of silane, propane and hydrogen, in the vapour phase, with the resultant deposition of the hexagonal-6H polytype $(\alpha \mathrm{SiC})$ on similar substrates $^{28}$. Both conductivity types are readily available by inclusion of suitable impurities during growth and $\mathrm{p}^{+}-\mathrm{n}$ and $\mathrm{n}^{+}-\mathrm{p}$ formats have been reported. Wessels and co-workers ${ }^{28}$ demonstrate strong blue emission in the former at $2.72 \mathrm{eV}$, close to band gap, and a yellow, $2.11 \mathrm{eV}$, emission in the latter, presumably associated with deep impurity centres in the n-type substrate. A singular feature of $\mathrm{SiC}$ is its existence in at least fifty polytype crystal forms, of which about six are fairly common, characterised by the alternation between hexagonal or cubic close-packed atomic layers. Each polytype has a distinct band gap ranging from $2.39 \mathrm{eV}$ in its cubic form (polytype 3C) to $3.26 \mathrm{eV}$ in its zincite form (polytype $4 \mathrm{H})^{27,29}$ an intermediate value appropriate to the common $8 \mathrm{H}$ material is quoted in Figure 3. While available in large quantities as an abrasive or refractory material the refining of $\mathrm{SiC}$ to semiconductor grade in quantity is a formidable problem, although LEDs have been sporadically 
offered by manufacturers. Any future reintroduction of the material on a commercial scale presumably depends upon successful development of the recently introduced low temperature epitaxy technique ${ }^{30}$.

\subsubsection{Cadmium sulphide}

Cadmium sulphide has a long history in optoelectronic devices, largely because of the high photoconductive quantum gains of which it is capable $^{31}$. Straightforward methods of preparation exist by which metallic cadmium is reacted with hydrogen disulphide to yield pure material in either single crystal or powder forms ${ }^{32,33}$. Again only n-type material can be grown, the introduction of notionally acceptor type impurities is met by almost total autocompensation giving an insulating n-type behaviour. Injection at a graded heterocontact is available in vapour grown $\mathrm{CdS}-\mathrm{ZnTe}{ }^{34}$ and $\mathrm{CdS}-\mathrm{ZnSe}{ }^{35}$ heterojunctions from which room temperature $1.79 \mathrm{eV}$ (red) emission is obtained. Because of the difficulties of electrical excitation in this material, monotypism compounded with the presence of high densities of trapping and storage centres ${ }^{36,37}$ (upon which photoconductive gain depends) and the low efficiency of radiative recombination, its exploitation in electroluminescent devices has not been feasible.

\subsubsection{Zinc chalcogenides}

All three zinc-based II-VI compounds in the range of interest $(\mathrm{ZnTe}, \mathrm{ZnSe}, \mathrm{ZnS})$ present the familiar problem of the impossibility of fabricating usable $\mathrm{p}-\mathrm{n}$ homojunctions in the material (other than by ion implantation). Pure single crystal materials may however be formed by a variety of means ${ }^{38}$, chemical methods at moderate temperatures being preferred, since all these materials have high melting points and a strong tendency to dissociate. Thin film deposition, in single crystal form, is also possible. The telluride occurs only as a p-type semiconductor, and the others only as n-type.

Work on the zinc selenide-zinc telluride combination ( $7 \%$ lattice mismatch ${ }^{38}$ ) has demonstrated that both vapour phase epitaxial growth of $\mathrm{ZnTe}$ on $\mathrm{ZnSe}^{39}$ and the evaporation of polycrystalline $\mathrm{ZnSe}$ onto $\mathrm{ZnTe}{ }^{40}$ yield diodes with characteristic red-orange emission from $\mathrm{ZnTe}$ at $1.98 \mathrm{eV}$. In addition the weaker green emission was observed in the evaporated diodes, but blue $\mathrm{ZnSe}$ emission has only been achieved in diodes cooled to liquid nitrogen temperatures ${ }^{41}$. Particularly high quantum efficiencies are obtained from $\mathrm{ZnTe}-\mathrm{CdSe}$ heterojunctions, external values up to $1.6 \%$ have been reported ${ }^{42}$ but only at $77^{\circ} \mathrm{K}$.

The selenide similarly cannot be counterdoped, although electroluminescence is quite readily attainable by excitation from either reverse biased Schottky diodes or heterojunctions. In the former, a broad spectrum ranging from $0.4 \mathrm{eV}$ (infra-red) to $0.65 \mathrm{eV}$ (blue/green) is observed 43,44 . Efficiencies may be good, but control of uniformity of emission close to breakdown and control of colour are not easy in practice. For MIS operation an important requirement is that the insulator film is sufficiently thin, about $50 \AA$ or less, to permit electron tunnelling through it. Unfortunately, it is extremely difficult to produce uniform films of this thickness and, as tunnel probability is a strong exponential function of reciprocal thickness, emission in practical $\mathrm{ZnSe}$ diodes $^{45}$, is extremely irregular. It may be that future work on coating by oxidation, nitridation, etc. as employed in silicon technology, may revive this type of device. Vapour phase epitaxial $\mathrm{Cu}_{2} \mathrm{Se}$ fused into $\mathrm{ZnSe}$ substrates emits in the $1.95 \mathrm{eV}$ (red), $2.19 \mathrm{eV}$ (orange) and $2.35 \mathrm{eV}$ (yellow/green) spectral regions $^{35}$.

The sulphide, with the widest band gap in this group, $3.84 \mathrm{eV}$ in zinc blende structure, 3.91 in wurtzite ${ }^{46}$, has important uses as a phosphor in colour T.V. tubes, for which application silver is introduced as dopant and strong blue cathodoluninescence is observed. In solid state display devices $\mathrm{ZnS}$ finds application in DCEL panels. Vecht and co-workers 47,48 have investigated many aspects of this type of device and now report usable large area displays with about $0.1 \%$ power efficiency corresponding to $500 \mathrm{~mL} / \mathrm{W}$, rather better than the best available yellow/green LEDs in the same spectral region but requiring up to $100 \mathrm{~V}$ bias (at low current) to achieve this performance. A recent development in the technology of these panels is their formation by suspending $\mathrm{Mn}, \mathrm{Cu}$ and $\mathrm{Al}$ doped $\mathrm{ZnS}$ in flexible PMMA sheets ${ }^{4}$.

\subsubsection{Zinc oxides and orthosilicate}

Zinc oxide, $\mathrm{ZnO}$, and zinc orthosilicate, $\mathrm{ZnSiO}_{4}$, differ somewhat from the other materials listed above in that both are primarily known as phosphors in large screen applications. Unfortunately, neither is ambipolar although a degree of p-type semi-insulating characteristics may be induced in the oxide by implantation of phosphorus ions. A similar technique is reported to give room temperature 
electroluminescence in forward biased $\mathrm{ZnSe} \mathrm{p}-\mathrm{n}$ junctions at $0.63 \mu \mathrm{m}$ (red) with a $0.01 \%$ external quantum efficiency ${ }^{50}$. There is a growing interest in the use of coatings of these phosphors excited from silicon substrates. The value of any successful device made in this way is obvious, the luminescent component can be integrated directly into the drive and address circuits and can be fabricated at some point in the silicon processing chain ${ }^{51}$. Three problems have to be overcome before such a device is practicable. First, it must be possible to form the activated phosphor on or in the silicon surface. Secondly, the silicon must be capable of providing electrons at the correct energy and in sufficient density to excite the phosphor. Thirdly, the interface must be such as to allow the carriers to excite the phosphor without large reduction in numbers through trapping and recombination or in energy through scattering.

Phosphor coatings can be provided by deposition and by silicon surface conversion. Sputtering at R.F. frequencies is a convenient means of depositing good quality uniform thin films of, particularly, ready activated $\mathrm{ZnO}$ on silicon ${ }^{52,53}$.

Zinc oxide is inexpensive because of its widespread industrial and medical use. It has been exploited in electro-photography which in turn, has revived interest in its properties as a semiconductor ${ }^{54}$. Furthermore its development in acoustoelectric transducers has built up a considerable literature on sputter deposition in pure thin-film form ${ }^{5}$.

Early work on CRTs had shown that $\mathrm{ZnO}$ was uniquely capable of cathodoluminescence at low excitation voltages, around $1 \mathrm{eV}$ or less 56,57 but since this was not a critical requirement it was soon superseded by materials with better luminescent properties. It has now been recognised that the chemisorption and desorption of excess oxygen ions at the surfaces of $\mathrm{ZnO}$ crystallites 58,59 is responsible for the phenomenon of high conductivity in powder layers and probably for the low $(\sim 1 \mathrm{eV})$ cathodoluminescence threshold.

The unique low excitation energy in $\mathrm{ZnO}$ may be used in the future to solve the second problem of device fabrication outlined previously; that the silicon substrate must be able to provide electrons of sufficient energy to excite the phosphor. The extraction of hot carriers into surface oxides, over a larger $(3.25 \mathrm{eV})$ interface barrier and into nitrides in exactly this way has been verified experimentally by a number of authors ${ }^{60-63}$, which is encouraging but does not mean that the same will be true of other surface layers. Zinc oxide, which possesses the

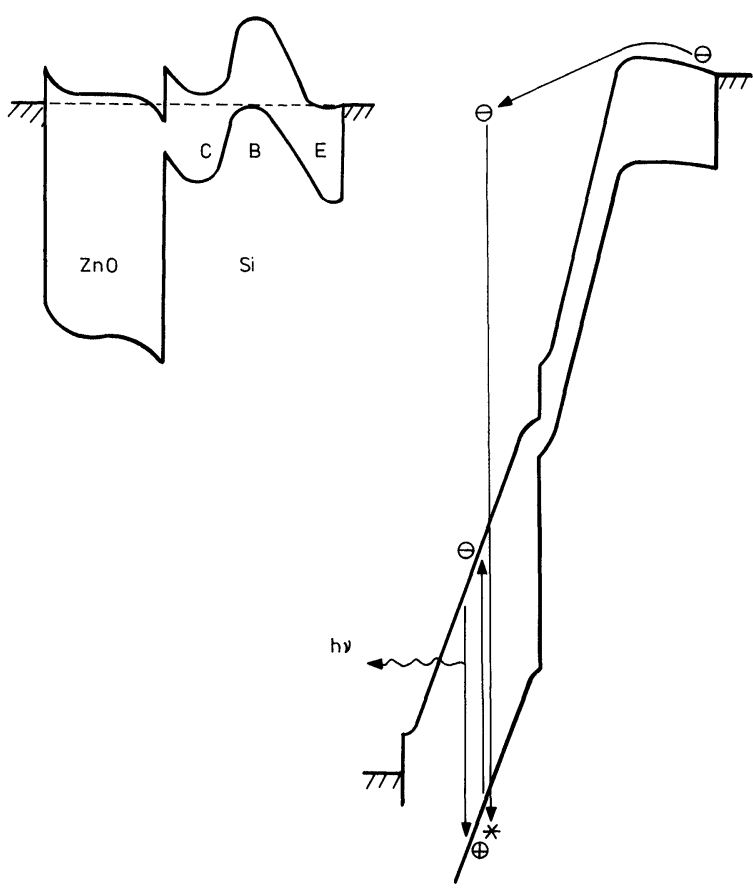

FIGURE $4 \quad \mathrm{Si}-\mathrm{ZnO}$ light emitter.

necessary qualities of ease of deposition and excitation has a favourable band alignment in the $\mathrm{ZnO}-\mathrm{Si}$ heterojunction. Figure 4a shows the band profile of an $n-p-n \mathrm{Si}-\mathrm{nZnO}$ structure, with all three features, the latter being fortuitously provided by the large work function of $\mathrm{ZnO}^{64}$ and hence large downward step from the Si layer. The proposed operating arrangement 65,66 is as illustrated in Figure $4 b$. The emitter-base junction supplies a quantity of electrons to the base-collector junction where they are accelerated towards the surface. Given that up to $50 \mathrm{~V}$ can be dropped across a $0.5 \mu \mathrm{m}$ collector layer and a comparable voltage is supportable in a $\mathrm{ZnO}$ film of equal thickness, it should then be possible to excite the phosphor and have substantial energy to spare since $1 \mathrm{eV}$ is sufficient for low voltage cathode ray tubes.

Morant and Woods ${ }^{67}$ have developed a technique whereby silicon is first oxidised, metallic zinc is evaporated and a further heat cycle converts this to the orthosilicate $\mathrm{ZnSiO}_{4}$. This is the $\mathrm{P} 1$ phosphor (see Section 3.1), which can be activated during growth by including manganese in the metal film with a 
resultant phosphor as good as or better than available powdered Willemite. The problem of complete conversion, i.e. no $\mathrm{SiO}_{2}$ remaining at the interface, has not yet been solved. As an alternative to excitation from the inverted bipolar structure preferred for $\mathrm{ZnO}$ these authors have considered devices in which the phosphor is excited from an avalanche plasma close to the surface in transverse FET or impatt arrangements.

This class of device, once developed, may bring together existing technology in the low-voltage phosphor heterojunction and $\mathrm{Si}$ processing areas together in such a way as to open up the prospect of silicon based electroluminescent devices.

\section{CONCLUSIONS}

LEDs have relatively low power efficiency, difficulties in supply storage over a typical frame time, and can only be fabricated in small assemblies of discrete elements. These and other factors combine to preclude them from large area display applications where the stalwart CRT and newer technologies of ferroelectrics, electrophoretics, etc. are in trinsically better suited to the job.

It is desirable to improve the device technology of small alphanumeric arrays and indicators in several ways. Firstly, sources emitting in the spectral region between yellow/green and violet may be useful

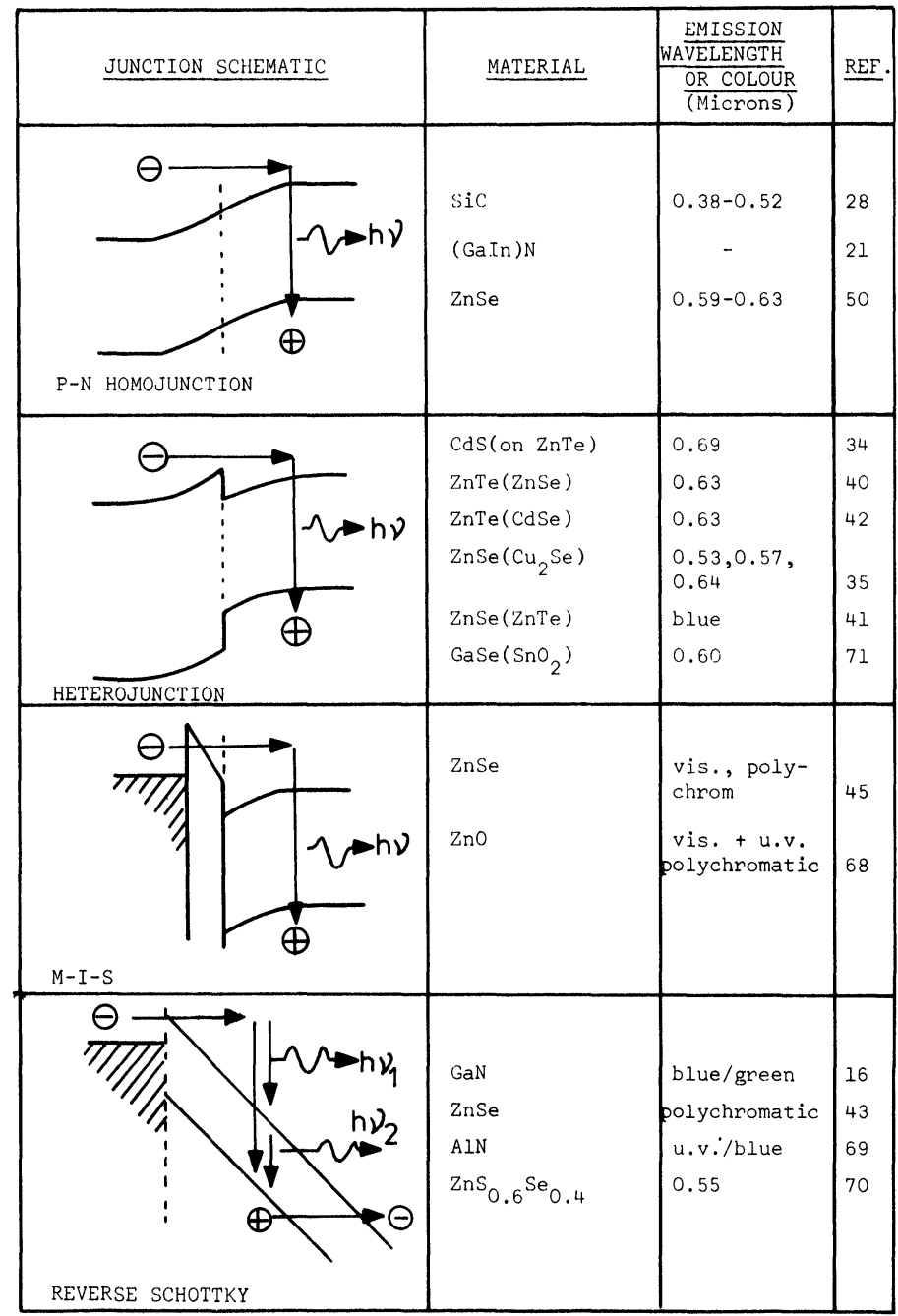

FIGURE 5 State of the art in novel devices/materials. 
additions to the colour range presently available. Secondly, efficiencies in the visible spectrum comparable to those obtainable from gallium arsenide in the infra-red would represent a significant improvement. Thirdly, a technique by which alphanumerics could be incorporated into silicon ICs as a standard processing step could greatly improve production efficiency and eventually reduce costs.

It has been shown that of the six material groups considered, one type, $(\mathrm{GaAl})$ As is in common use, $\mathrm{GaN}$ and its variants have distinct possibilities and future work may show that zinc oxide based structures are also of interest. Figure 5 shows the device and material technologies currently being investigated in all areas. Choice of colour at high efficiency is possible by virtue of the range of poly types of $\mathrm{SiC}$ and also, in the case of $\mathrm{GaN}$, by the range of deep dopant centres which are possible and which will cause $\mathrm{GaN}$ to luminesce. The technology of both materials is difficult, however, and only industrially viable if significant advances can be made.

The economic factors involved in bringing either material to large scale production are more serious than those involved in the development of III-V compounds and this has to be offset against likely demand.

High efficiency in the visible spectrum has been the prerogative of phosphors, some of which are powder versions of II-VI semiconductors. The electroluminescent excitation of these is prevented, for the most part, by inability to substantially counterdope any of them. There are, fortunately, means of achieving minority carrier injection other than by forward biassing a $\mathrm{p}-\mathrm{n}$ homojunction. Heterojunctions, MIS structures and reverse biased Schottky diodes are three alternative classes of device and $\mathrm{ZnSe}$ appears to be the most popular luminescent material for all three. Here again, the technology needs considerable development.

Though a comparatively new idea, the excitation of phosphors, $\mathrm{ZnO}$ and $\mathrm{ZnSiO}_{4}$ in particular, from silicon substrates is perhaps the most hopeful sign of plausible innovation in semiconductor display devices. This approach however, is still at an early research stage, so it is realistic to conclude that the contribution of new semiconductor materials and devices in display applications will be small, at least in the near future.

\section{REFERENCES}

1. E. I. Gordon and L. K. Anderson, New display technologies, Proc. IEEE, 61, 807 (1973).
2. L. T. Creagh, A. R. Konetz and R. A. Reynolds, Performance characteristics of nematic liquid crystal display devices, IEEE Trans. Electron. Devices, 672 (1971).

3. A. H. Meitzler, J. R. Maldonado and D. B. Fraser, Image storage display devices using fine grain ferroelectric ceramics, Bell. Syst. Tech. J., 49, 953 (1970).

4. G. Marie, Un nouveau dispositif de restitution d'images utilisant un effet electro-optique: Le tube Titus, Philips Res. Repts., 22, 110 (1967).

5. G. F. Weston, Glow discharge matrix displays, Proc. 1971 Inst. Conf. Electro-optics (Brighton), 547 (1971).

6. Z. van Gelder and M. M. M. P. Mattheij, Principles and techniques in multi-color DC gas discharge displays, Proc. IEEE, 61, 1019 (1973).

7. I. Gorog, Cathodochromic display applications, $A p p l$. Opt., 9, 2243 (1970).

8. I. Ota, J. Ohnishi and M. Yoshiyama, Electrophoretic image display (EPID) panel, Proc. IEEE, 61, 832 (1973).

9. T. L. Tansley, in Semiconductors and Semimetals, Ed. Willardson and Beer (Publ. Academic Press, New York), 7, 293 (1971).

10. S. Larach and A. E. Hardy, Cathode ray tube phosphors, principles and applications, Proc. IEEE, 61, 915 (1973).

11. W. M. Yim, et al., Epitaxially grown AIN and its optical band gap, J. Appl. Phys., 44, 292 (1973).

12. Z. I. Alferov, et al., AlAs-GaAs heterojunction injection lasers with low room temperature thresholds, Sov. Phys-Semicond., 3, 1107 (1970).

13. I. Hayashi and M. B. Pannish, GaAs-GaAlAs lasers with low threshold at room temperature, J. Appl. Phys., 41, 150 (1970).

14. H. Nelson and H. Kressel, Improved red and infrared light emitting AlGaAs laser diode, Appl. Phys. Letts., 15 , 7 (1969).

15. M. G. Crawford and W. O. Groves, Vapour phase epitaxial materials for LED applications, Proc. IEEE, 61, 862 (1973)

16. J. I. Pankove, U.V. D.C. electroluminescence from $\mathrm{GaN}$, J. Luminesc., 5, 482 (1972).

17. J. I. Pankove, Luminescence in $\mathrm{GaN}, J$. Luminesc., 7, 114 (1973).

18. J. I. Pankove, Blue/green numeric displays using electroluminescent GaN, R.C.A. Review, 34, 336 (1973).

19. Y. Morimoto, Violet electroluminescence from $\mathrm{Mn}$ doped GaN point contact diodes, Jap. J. Appl. Phys., 13, 1307 (1974).

20. J. I. Pankove, E. A. Miller and J. E. Berkeyheiser, GaN electroluminescent diodes, R.C.A. Rev., 32, 383 (1971).

21. K. Osamura, et al., Fundamental absorption edge of $\mathrm{GaN}, \mathrm{InN}$ and their alloys, Solid State Commun., 11, 617 (1972).

22. J. M. Blonk, Fabrication of SiC LEDs, Mater. Res. Bull., 4, 5179 (1969).

23. R. W. Brander, A review of the merits of direct and indirect gap semiconductors for electroluminescent devices, Rev. Phys. Technol., 3, 145 (1972).

24. R. W. Brander, Fabrication of SiC electroluminescent displays, Mater. Res. Bull., 4, 5187 (1969).

25. P. J. Dean, Electroluminescence in semiconductors, Proc. IEEE, 62, 853 (1974).

26. A. A. Bergh and P. J. Dean, Light emitting diodes, Proc. IEEE, 60, 156 (1972).

27. E. E. Loebner, The future of electroluminescent solids in display, Proc. IEEE, 61, 837 (1973). 
28. B. Wessels, H. C. Gatos, A. F. Witt, Epitaxial growth of $\mathrm{SiC}$ by chemical vapour deposition, Conf. SiC, Miami Beach, USA (1973).

29. F. Herman, J. P. van Dyke and R. L. Kortum, Electronic structure and optical spectrum of SiC, Mater. Res. Bull., 4, 5167 (1969).

30. E. Machevskii, I. Neimare and I. Feltyn, The kinetics of cubic silicon carbide growth on silicon, Latv. PSR Zinat. Akad. Vestis, Fiz. Tech. Ser. (USSR), 1, 46 (1972).

31. R. H. Bube in Photoconductivity of Solids, J. Wiley, New York (1960).

32. F. A. Kroger, H. J. Vink and J. Volger, Temperature dependence of Hall effect and resistivity of CdS single crystals, Philips Res. Reps., 10, 39 (1955).

33. R. Frericks, The photoconductivity of incomplete phosphors, Phys. Rev., 72, 594 (1947).

34. T. Ota, K. Kobayashi and K. Takahashi, Light emitting mechanism of $\mathrm{ZnTe}-\mathrm{CdS}$ heterojunction diodes, $J$. Appl. Phys., 45, 1750 (1974).

35. T. Ota, K. Kobayashi and K. Takahashi, Light emitting diode of $\mathrm{ZnSe}-\mathrm{CdS}$ heterojunctions, Solid State Electron., 15, 1387 (1972).

36. R. H. Bube in Physics and Chemistry of II-VI Compounds, p. 655 (M. Aven and J. S. Prener eds.), Publ. North-Holland, Amsterdam (1967).

37. K. H. Nicholas and J. Woods, The evaluation of electron trapping parameters from conductivity glow curves in CdS, Brit. J. Appl. Phys., 15, 783 (1964).

38. B. Ray in II-VI Compounds, Publ. Pergamon, Oxford (1969).

39. H. J. Lozykowski, H. L. Ozkowski and F. Firzst, Bull. Acad. Pol. Sci., Ser. Math. Astron. and Phys., 21, 485 (1973).

40. G. Le Floch and H. Arnould, Electroluminescence dans une heterojunction $\mathrm{ZnTe}-\mathrm{ZnSe}$, Solid State Electron., 16, 941 (1973).

41. S. Fujita, et al., Blue electroluminescence in $\mathrm{ZnSe}-\mathrm{ZnTe}$ heterojunctions, Jap. J. Appl. Phys., 12, 1094 (1973).

42. P. A. Gashin and A. V. Simashkevich, 'SnTe-CdSe heterojunctions, II photoelectric and luminescent properties, Phys. Stat. Sol. (A), 19, 615 (1973).

43. J. W. Allen, 'Electroluminescence in reverse biased Schottky diodes, J. Luminesc., 7, 114 (1973).

44. K. Turvey and J. W. Allen, Light emission from hot electrons in ZnSe, J. Phys. C., 6, 2887 (1973).

45. A. G. Fischer, Injection electroluminescence in $\mathrm{ZnSe}$ metal-semiconductor diodes, Proc. 7th Int. Conf. Semicond., Paris, 4, 259 (1964).

46. O. Brafman and I. T. Steinberger, Determination of the absorption edges of $\mathrm{ZnS}$ polytypes, Appl. Phys. Lett., 7, $110(1965)$

47. A. Vecht, DC electroluminescence in $\mathrm{ZnS}$ and related compounds, J. Luminesc., 7, 213 (1973).

48. A. Vecht, et al., Direct current luminescence in $\mathrm{ZnS}$, Proc. IEEE, 61, 902 (1973).

49. J. M. Fikiet and J. L. Plumb, DC conduction and electroluminescence in dielectric embedded $\mathrm{ZnS}: \mathrm{Mn}$, $\mathrm{Cu}, \mathrm{Cl}, J$. Electrochem. Soc., 120, 1238 (1973).
50. Y. S. Park and B. K. Shin, Injection luminescence in phosphorus ion implanted $\mathrm{ZnSe} \mathrm{p}-\mathrm{n}$ junction diodes, $J$. Appl. Phys., 45, 1444 (1974).

51. T. L. Tansley and S. J. T. Owen, Potential developments in light emitting devices based on silicon, Microelectronics, 6, no. 4, 7 (1975).

52. J. Vuillod, Properties of $\mathrm{ZnO}$ films prepared by d.c. and r.f. sputtering, J. Vac. Sci. and Tech., 9, 87 (1971).

53. S. J. T. Owen and T. L. Tansley, University of Nottingham Electrical and Electronic Engineering Report, PHIB 1 (1975).

54. Z. M. Jarzebski in Oxide Semiconductors, Publ. Pergamon, Oxford (1973).

55. T. Hada, K. Wasa and S. Hayakawa, Structures and electrical properties of $\mathrm{ZnO}$ films prepared by low pressure sputtering, Thin Solid Films, 7, 135 (1971).

56. S. F. Kaisel and C. B. Clark, A luminescent screen for use with very low energy electrons, J. Opt. Soc. Amer., 44, 134 (1954).

57. R. E. Shrader and S. F. Kaisel, Excitation of zinc oxide phosphors by low-energy electrons, J. Opt. Soc. Amer. 44, 135 (1954).

58. I. Niikura, H. Watanabe, $\mathrm{M}$. Wada, Contact of $\mathrm{ZnO}$ thin films with Rhodamine B dye, Jap. J. Appl. Phys., 8, 755 (1969).

59. H. Watanabe, The influence of ambient oxygen on the electronic conductivity of $\mathrm{ZnO}$ thin films, Jap. J. Appl. Phys., 9, 418 (1970).

60. J. F. Verwey and R. P. Kramer, Atmos, an electrically reprogrammable ROM device, European Sol. State Dev. Res. Conf., Munich (1973).

61. G. Bosselaar, Charge injection into $\mathrm{SiO}_{2}$ from reverse biased junctions, Solid State Electron., 16, 648 (1973).

62. E. H. Nichollion, A. Goetzberger and C. N. Berglund, Avalanche injection currents and charging phenomena in thermal $\mathrm{SiO}_{2}$, Appl. Phys. Lett., 15, 174 (1969).

63. M. Pepper, Electron injection into $\mathrm{SiO}_{2}$ from an avalanching $\mathrm{p}-\mathrm{n}$ junction, J. Phys. D., 6, 2124 (1973).

64. R. K. Swank, Surface properties of II-VI compounds, Phys. Rev., 153, 844 (1967)

65. H. Kromer and W. I. Lehrer, Light emitting semiconductor heterojunction devices, U.S. Pat $3,488,542$ (1970)

66. J. R. A. Beale, Hot carrier electroluminescent devices, U.K. Pat. 1,392,536 (1975).

67. M. J. Morant and G. S. Edwards, The growth and properties of luminescent films on silicon, Solid State Electron., 16, 173 (1973).

68. T. Minami, M. Tanigawa, M. Yamanishi, T. Kawamura, Observation of ultra-violet luminescence from $\mathrm{ZnO}$ MIS diodes, Jap. J. Appl. Phys., 13, 1476 (1974).

69. R. F. Rutz, Blue and ultra-violet electroluminescent diode, IBM Tech. disclosure Bull., 17, 2800 (1975).

70. M. E. Ozan and J. Woods, Green electroluminescence of $\mathrm{Zn}_{0.6} \mathrm{Se}_{0.4}$, Appl. Phys. Letts., 25, 489 (1975).

71. C. Tatsuyama, H. Mizukami, S. Ichimura, Electroluminescence in forward biased $\mathrm{GaSe}-\mathrm{SnO}_{2}$ heterojunction, Jap. J. Appl. Phys., 13, 1925 (1974). 

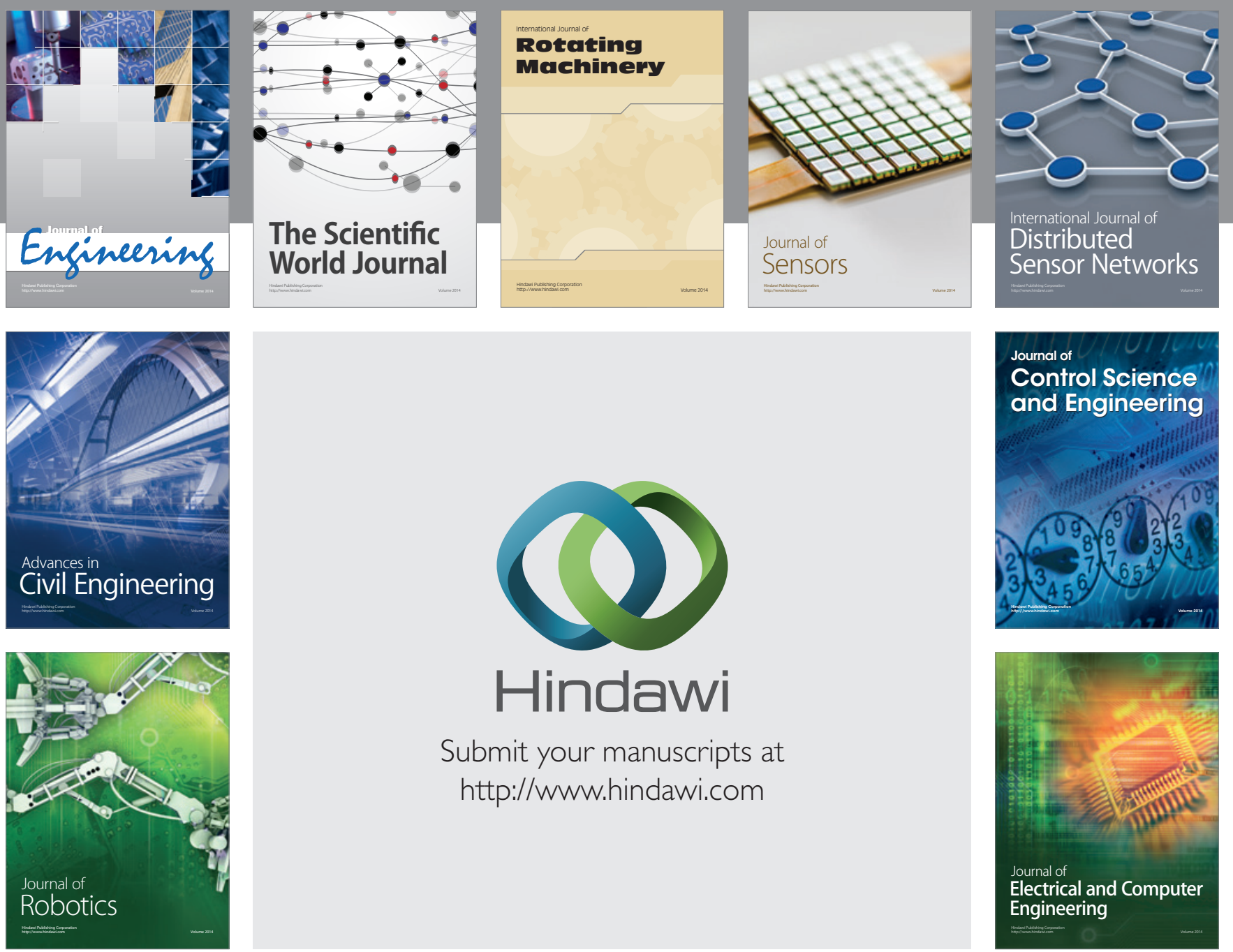

Submit your manuscripts at

http://www.hindawi.com
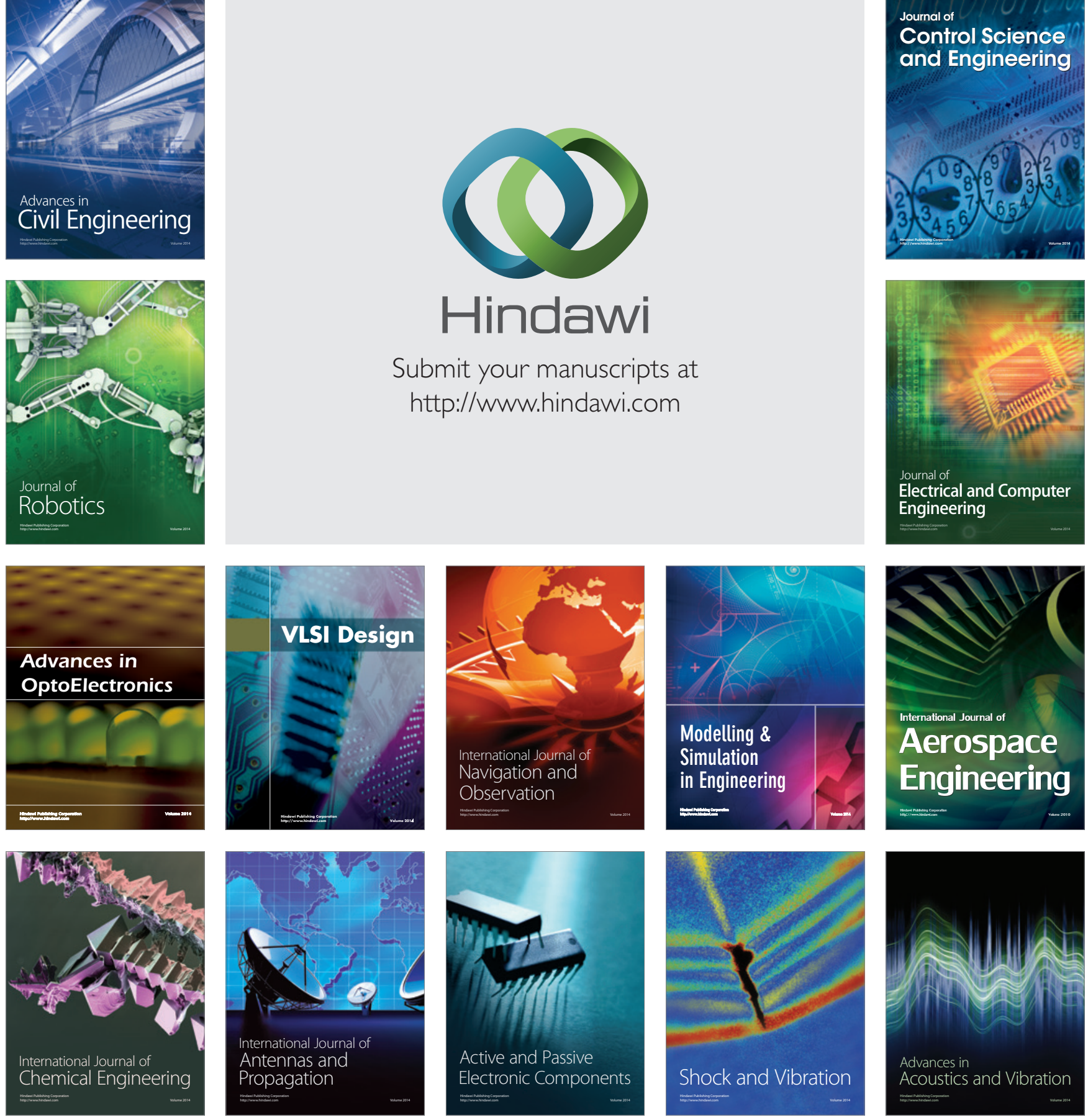